\title{
Fetomaternal outcome in preterm labour
}

\section{Nungsangtemjen, Kaushik Mahajan*, M. Rameswar Singh, Yaruiyam Mahongnao, Dylan G. Momin, Taneesha Subba}

Department of Obstetrics and Gynecology, Regional Institute of Medical Sciences, Imphal, Manipur, India

Received: 19 April 2021

Revised: 11 May 2021

Accepted: 12 May 2021

\section{*Correspondence:}

Dr. Kaushik Mahajan,

E-mail: Kaushik.rims@gmail.com

Copyright: (C) the author(s), publisher and licensee Medip Academy. This is an open-access article distributed under the terms of the Creative Commons Attribution Non-Commercial License, which permits unrestricted non-commercial use, distribution, and reproduction in any medium, provided the original work is properly cited.

\section{ABSTRACT}

Background: Preterm birth is the leading cause of infant morbidity and mortality in the world. It affects not only the immediate neonatal period but also affects infancy, childhood and even adulthood. The aim of the study was to ascertain the causes and outcome of preterm labor and delivery and also the neonatal outcome.

Methods: A hospital based cross-sectional study was conducted among patients who entered the third trimester of pregnancy and diagnosed as a case of threatened preterm labor or preterm labor from September 2017 to August 2019 in the department of obstetrics \& gynaecology in collaboration with department of paediatrics, Regional institute of Medical Sciences, Imphal. Detailed clinical history and socio-demographic profile were recorded in pre-designed proforma. General physical examination and systemic examination and obstetrical examination was carried out for the participants.

Results: Out of 918 preterm births $88.9 \%$ of neonates between the gestation period 28 weeks and $<32$ weeks were admitted to NICU. $48.8 \%$ of the neonates were having low birth weight. $23.8 \%$ of neonates required NICU admission and the most common neonatal complications were sepsis (5.2\%), asphyxia (4\%), jaundice (4\%) and hyaline membrane disease $(1.7 \%)$. Apgar score significantly improved as the period of gestation increased at 5 minute and 10 minutes $(\mathrm{p}=0.006$ and $\mathrm{p}<0.001$ respectively). The overall mortality among preterm births was $8.1 \%$ and only $3.7 \%$ neonatal deaths were seen in gestational age 34 weeks to $<37$ weeks, whereas $24.1 \%$ and $22.2 \%$ mortality were seen in 32 weeks to $<34$ weeks and 28 weeks to $<32$ weeks of gestation $(\mathrm{p}=<0.001)$.

Conclusions: Preterm infants are at high risk for overall morbidity and mortality compared with term infants. Proper antenatal care, clinical suspicion, early detection and correction of risk factors, institutional delivery and good neonatal care facilities can improve the outcome of preterm labour.

Keywords: Preterm labour, Apgar score, Cross sectional study, Fetomaternal outcome

\section{INTRODUCTION}

Preterm birth (PTB) is the leading cause of infant morbidity and mortality in the world. ${ }^{1}$ It affects not only the immediate neonatal period but also affects infancy, childhood and even adulthood. It can affect physical health, cognitive and behavioural dimensions, making it one of the most significant challenges for modern public health. ${ }^{2,3}$ The WHO defines preterm birth as any birth before 37 completed weeks of gestation or fewer than 259 days since the first day of woman's last menstrual period
(LMP). ${ }^{4}$ According to WHO, every year about 15 million babies are born prematurely around the world and that is more than 1 in 10 of all babies born globally. Almost 1 million children die each year due to complications of preterm birth (2013).

Across 184 countries, the rate of preterm birth ranges from $5 \%$ to $18 \%$ of babies born. In India, out of 27 million babies born every year (2010 data), 3.6 million babies born are premature, of which 303,600 do not survived due to complications. ${ }^{4}$ Of all early neonatal deaths that are not 
related to congenital malformations, $28 \%$ are due to preterm birth. Children who are born prematurely have higher rates of cerebral palsy, sensory deficits, learning disabilities and respiratory illnesses compared with children born at term. ${ }^{5-7}$

Due to continued innovation in neonatal intensive care facilities and obstetric interventions, fetal survival is now possible even at 20 weeks gestation in developed countries. However, in even the best set up in developing countries, survival is rare below 28 weeks of gestation. Incidence of preterm labor is $23.3 \%$ and of preterm delivery $10-69 \%$ in India. It is raising world over because of increased frequency of multiple births due to assisted reproductive techniques (ART), more working mothers, increasing psychological stress and medically induced prematurity. ${ }^{8}$

More than three-quarters of preterm/premature babies can be saved with often inexpensive care such as essential care during child birth, antenatal steroid injections (given to pregnant women at risk of preterm labor under set criteria to strengthen the babies lungs) and postnatal care like kangaroo mother care (the baby is carried by the mother with skin-to-skin contact and frequent breastfeeding), and basic care for infections and breathing difficulties. Identification of risk factors in women with improved care before, between and during pregnancies; better access to contraceptives and increased empowerment/ education can further decrease the preterm birth rate (the number of preterm births divided by the number of live births). ${ }^{4}$

In our part of the country many preterm births are taking place but the exact data are lacking. Hence this study is being planned to ascertain the causes and outcome of preterm labor and delivery and also the neonatal outcome.

\section{METHODS}

A hospital based cross-sectional study was conducted among patients who entered the third trimester of pregnancy and diagnosed as a case of threatened preterm labor or preterm labor from September 2017 to August 2019 in the department of obstetrics \& gynaecology in collaboration with department of paediatrics, Regional institute of Medical Sciences, Imphal. Patients with preterm newborns with any congenital malformation, term pregnancy, cases with malpresentation, antepartum haemorrhage and uterine anomaly, not giving consent or not willing to participate were excluded. The study was conducted after obtaining permission from the Research Ethics Board, RIMS, Imphal.

\section{Sample size and sampling}

Assuming the prevalence of of preterm birth in India as $13 \%$, the sample size was estimated to be 172 at $95 \%$ confidence level and a precision of $5 \%$, using the formula for diagnostic tests. All the Patients who entered the third trimester of pregnancy and are diagnosed as a case of threatened preterm labor or preterm labor were included in this study until the sample size was reached.

\section{Study procedure}

After obtaining informed consent from the participants, the detailed clinical history including premature rupture of membranes, vaginal Infections, urinary infections, multiple gestation (twins, triplets), polyhydramnios, maternal disease, extremes of age, history of abortions, history of preterm deliveries, short stature, maternal weight and sociodemographic profile were then recorded. Following the socio- demographic and clinical characteristics, general physical examination (pallor, oedema, neck glands, thyroid) and systemic examination and obstetrical examination was carried out for the participants.

Fetal outcome is recorded in terms of: (a) Apgar score at birth; (b) fetal weight; (c) NICU admission; (d) perinatal outcome. Maternal outcome is recorded in terms of: (a) gestational age at the time of delivery, b) duration of labor; (c) mode of delivery: vaginal/assisted vaginal delivery/caesarean section; (d) complications if any. All the routine investigations including complete haemogram, urine routine examination, liver and kidney function tests, $\mathrm{ABO}$ grouping and $\mathrm{Rh}$ typing, blood sugar estimation, thyroid profile along with necessary investigations like ultrasonography (trans-abdominal) were also performed. Data was recorded in a pre-designed proforma.

\section{Statistical analysis}

Data were checked for completeness and consistency. Data was analysed using SPSS for windows version 21 (IBM. Corp 1995, 2012). Descriptive statistical tools like mean, percentage and proportion were used. Association between preterm labor and fetomaternal outcome were analysed using chi square test. $\mathrm{P}$ value $<0.05$ was considered as significant.

\section{RESULTS}

In this study, over a period of one and half years (September 2017-March 2019) there were 13,810 live births, out of which 918 were pre-term births. So, incidence of preterm birth is $6.6 \%$ in our study.

Table 1 shows almost half of the mothers (49.4\%) were primipara and one fourth of the mothers $(27.9 \%)$ had previous history of abortion. Majority of the mothers $(77.9 \%)$ were late preterm cases (i.e gestation between 34 weeks and $<37$ weeks). Maximum mothers (95.3\%) did not have any previous history of preterm births.

Table 2 shows most common risk factor was PPROM $(47.7 \%)$, which almost half of the mothers had, followed by Hypertension (18.6\%), UTI (7.6\%) and twin pregnancy $(7.6 \%)$, etc. 
Table 1: Mothers characteristics ( $N=172)$.

\begin{tabular}{|l|l|}
\hline Characteristics & N $(\%)$ \\
\hline Parity & $85(49.4)$ \\
\hline Primi & $82(47.7)$ \\
\hline Multi para & $5(2.9)$ \\
\hline Grand multipara & \\
\hline History of abortion & $124(72.1)$ \\
\hline No & $48(27.9)$ \\
\hline Yes & \\
\hline Period of gestation (in weeks) & $9(5.2)$ \\
\hline 28 to <32 & $29(16.9)$ \\
\hline 32 to <34 & $134(77.9)$ \\
\hline 34 to <37 & $119(69.2)$ \\
\hline Mode of delivery & $5(2.9)$ \\
\hline Normal vaginal delivery & $48(27.9)$ \\
\hline Elective caesarean & \\
\hline Emergency caesarean & $8(4.7)$ \\
\hline Previous history of preterm & $164(95.3)$ \\
\hline Yes
\end{tabular}

Table 2: High risk factors for preterm labour $(\mathrm{N}=172)$.

\begin{tabular}{|l|l|}
\hline Risk factors & N $(\%)$ \\
\hline $\begin{array}{l}\text { Preterm premature rupture of } \\
\text { membrane (PPROM) }\end{array}$ & $82(47.7)$ \\
\hline PIH & $32(18.6)$ \\
\hline UTI & $13(7.6)$ \\
\hline Twins & $13(7.6)$ \\
\hline Idiopathic & $7(4.1)$ \\
\hline Gestational diabetes mellitus & $6(3.5)$ \\
\hline Anaemia & $5(2.9)$ \\
\hline Polyhydramnios & $4(2.3)$ \\
\hline Short stature & $4(2.3)$ \\
\hline Thyroid disorders & $3(1.7)$ \\
\hline Vaginal infections & $3(1.7)$ \\
\hline
\end{tabular}

Table 3: Complications of the neonate's baby $(\mathrm{N}=172)$.

\begin{tabular}{|ll|}
\hline Complications & $\mathbf{N}(\%)$ \\
\hline Low birth weight & $84(48.9)$ \\
\hline Very low birth weight & $16(9.3)$ \\
\hline Early onset sepsis & $9(5.2)$ \\
\hline Hyperbilirubinaemia & $4(2.3)$ \\
\hline LBW with asphyxia & $4(2.3)$ \\
\hline $\begin{array}{l}\text { Birth asphyxia with neonatal } \\
\text { jaundice }\end{array}$ & $3(1.7)$ \\
\hline Hyaline membrane disease & $3(1.7)$ \\
\hline
\end{tabular}

Table 3 shows majority $(48.9 \%)$ of the neonates had low birth weight, $9.3 \%$ of the neonates had very low birth weight, $5.2 \%$ of the neonates were complicated with early onset sepsis. Other complications observed were hyperbilirubinaemia (2.3\%), LBW with asphyxia (2.3\%), etc.
Table 4 shows $88.9 \%$ of neonates of cases between the gestation period 28 weeks and $<32$ weeks were admitted to NICU, while the trend significantly decreased as the gestational age increased $(\mathrm{p}<0.001)$.

Table 4: Association between POG and NICU admission $(\mathrm{N}=172)$.

\begin{tabular}{|c|c|c|c|}
\hline \multirow[b]{2}{*}{ POG } & \multicolumn{2}{|c|}{ NICU admission (N\%) } & P value* \\
\hline & Yes & No & \multirow{4}{*}{$<0.001$} \\
\hline 28 to $<32$ & $8(88.9)$ & $1(11.1)$ & \\
\hline 32 to $<34$ & $16(55.2)$ & $13(44.8)$ & \\
\hline 34 to $<37$ & $17(12.7)$ & $117(87.3)$ & \\
\hline
\end{tabular}

*Chi square test

Table 5 shows majority of the neonates were having low birth weight and this trend significantly decreased as the gestation age increased $(\mathrm{p}<0.001)$.

Table 6 shows $91 \%$ of the neonates of cases who were in the late preterm period had Apgar score 7 or more in the 1 st minute and is found to be statistically significant.

Table 5: Association between POG and birth weight $(\mathrm{N}=172)$.

\begin{tabular}{|c|c|c|c|c|}
\hline \multirow[t]{2}{*}{ POG } & \multicolumn{3}{|c|}{ Birth weight (BW) (N\%) } & $\begin{array}{l}\mathbf{P} \\
\text { value* }\end{array}$ \\
\hline & VLBW & LBW & Normal & \\
\hline 28 to $<32$ & $3(33.3)$ & $6(66.7)$ & $0(0)$ & \\
\hline 32 to $<34$ & 8 (27.6) & $18(62.1)$ & $3(10.3)$ & \\
\hline 34 to $<37$ & $5(3.7)$ & $60(44.8)$ & $\begin{array}{l}69 \\
(51.5)\end{array}$ & $<0.001$ \\
\hline
\end{tabular}

*Chi square test

Table 6: Association between POG and Apgar at $1 \min (\mathrm{N}=172)$.

\begin{tabular}{|llll|}
\hline POG & \multicolumn{2}{l}{ Apgar at $\mathbf{1}$ min $(\mathbf{N} \%)$} & P value* \\
\cline { 1 - 3 } $\mathbf{2 8}$ to $<32$ & $2(22.2)$ & $7(77.8)$ & \multirow{2}{*}{$<0.001$} \\
\hline $\mathbf{3 2}$ to $<34$ & $11(37.9)$ & $18(62.1)$ & \\
\hline $\mathbf{3 4}$ to $<37$ & $12(9)$ & $122(91)$ & \\
\hline
\end{tabular}

*Fisher exact test

Table 7 shows Apgar score at 5 minutes significantly improved as the period of gestation increased.

Table 7: Association between POG and Apgar at $5 \min (\mathrm{N}=172)$.

\begin{tabular}{|c|c|c|c|}
\hline \multirow{2}{*}{ POG } & \multicolumn{2}{|c|}{ Apgar at $5 \mathrm{~min}(\mathrm{~N} \%)$} & P value* \\
\hline & $<7$ & $\geq 7$ & \multirow{4}{*}{$<0.006$} \\
\hline 28 to $<32$ & $2(22.2)$ & $7(77.8)$ & \\
\hline 32 to $<34$ & $5(17.2)$ & $24(82.8)$ & \\
\hline 34 to $<37$ & $5(3.7)$ & $129(96.3)$ & \\
\hline
\end{tabular}

*Fisher exact test 
Table 8 shows Apgar score at 10 minutes significantly improved as the period of gestation increased.

Table 9 shows birth weight is significantly associated with mortality as no deaths were reported in babies who weighed $>2 \mathrm{~kg}(\mathrm{p} \leq 0.01)$.

Table 8: Association between POG and Apgar at $10 \min (\mathrm{N}=172)$.

\begin{tabular}{|c|c|c|c|}
\hline \multirow{2}{*}{ POG } & \multicolumn{2}{|c|}{ Apgar at $10 \mathrm{~min}(\mathrm{~N} \%)$} & P value $*$ \\
\hline & $<7$ & $\geq 7$ & \multirow{4}{*}{$<0.006$} \\
\hline 28 to $<32$ & $1(11.1)$ & $8(88.9)$ & \\
\hline 32 to $<34$ & $4(13.8)$ & $20(86.2)$ & \\
\hline 34 to $<37$ & $0(0)$ & $134(100)$ & \\
\hline
\end{tabular}

Table 9: Association between birth weight and morality $(\mathrm{N}=172)$.

\begin{tabular}{|c|c|c|c|}
\hline \multirow{2}{*}{ BW (kg) } & \multicolumn{2}{|c|}{ Mortality } & P value * \\
\hline & Yes & No & \multirow{5}{*}{$<0.01$} \\
\hline$<1.5$ & $9(56.3)$ & $7(43.8)$ & \\
\hline 1.5 to $<2$ & $5(17.2)$ & $24(82.8)$ & \\
\hline 2 to $<2.5$ & $0(0)$ & $55(100)$ & \\
\hline$>2.5$ & $0(0)$ & $72(100)$ & \\
\hline
\end{tabular}

*Fisher exact test

\section{DISCUSSION}

During the study period there were 13,810 live births. Out of these $918(6.6 \%)$ were preterm births, which is comparable to an Iranian study done by Alijahan et al $(5.1 \%)$. Singh et al and Satija et al has reported higher incidence rate, $20.9 \%$ and $20.4 \%$ respectively but they included deliveries at <28weeks of gestation. ${ }^{8,10,12}$ Studies done by Garg et al and Naik et al observed higher incidence rate of preterm, $11.16 \%$ and $11.56 \%$, as compared to our study. ${ }^{13,14}$

Maximum number of mothers $(61.1 \%)$ were in the age group of 20-29 years in this study which is comparable to a study done by Fernandes et al $(67.9 \%) .{ }^{9}$ Extremes of age group (i.e $<20$ and $>35$ years of age), which play a large role in PTB, accounted for $25 \%$ of the cases which is slightly higher when compared to studies done by Fernandes et al and Shetty et al $15.8 \%$ and $14.2 \%$ respectively. ${ }^{9,15}$ This could be because of higher absolute number of cases in our study who were $>35$ years of age i.e 30/172(17.4\%). Though other studies done by Samim et al reported higher extremes of age for $36.5 \%$ of cases. ${ }^{17}$

In our study, almost two third $(71.5 \%)$ of the mothers belonged to low socio-economic status. Similar findings were reported in studies done in India. ${ }^{11,16} 49.4 \%$ of the mothers were primigravidas in our study, while multigravidas accounted for $50.6 \%$. The findings in the present study were consistent with the study Singh et al where $47 \%$ were primigravida and $53 \%$ were multiparous. ${ }^{8}$ Grand multipara cases accounted only for
$2.9 \%$ of the total cases. Similar findings were also observed in studies done by Fernandes et al. ${ }^{9}$ On the contrary, Shlomo et al in Israel observed that preterm delivery rate was much higher $(93 \%$ among gravid $>5) .{ }^{18}$ The comparative lower rate of grand-multiparas among the patients in our setting might be due to motivation to adopt family planning.

In this study, $20.9 \%$ of the mothers had previous history of one abortion, whereas $7 \%$ of the mothers had two or more abortion. These findings correlated with studies done in India and Epipage study. ${ }^{15,19}$ The commonest obstetrical risk factor in our study was preterm premature rupture of membrane (PPROM) accounting for almost half of the cases $(47.7 \%)$. Pool et al and Singh et al found approximately $30 \%$ and $25.9 \%$ respectively, of pre-term births associated with rupture of membrane. ${ }^{8,20}$ The second most common risk factor in our study was pregnancy induced hypertension (PIH) which accounted for $18.6 \%$ of the cases. Similar findings $(21.07 \%)$ were observed in studies done by Fernandes et al, Shrestha et al at $13.3 \%$ and Taskeen et al at $14 \%$. The slightly higher incidence of hypertensive disorders in our study maybe due to the fact that almost half of the cases were either referred or were unbooked cases with no proper antenatal checkup. ${ }^{9,21,22}$

Genitourinary infections have been reported to be one of the commonest risk factors in literature. Wright et al identified urinary tract infections (UTI) in $7 \%$ of PTB, similar to our study where $7.6 \%$ of the cases had UTI. ${ }^{24}$ Singh et al found genitourinary infection as the second commonest cause $(20.7 \%)$, reporting UTI and vaginal infections in $8.4 \%$ and $12.25 \%$ cases respectively. ${ }^{8}$

Almost one fourth $(23.8 \%)$ of neonates required neonatal intensive care unit (NICU) admission and the most common neonatal complications were sepsis (5.2\%), asphyxia (4\%), jaundice (4\%) and hyaline membrane disease $(1.7 \%)$. Garg et al observed $84 \%$ of neonates requiring NICU admission with complications of jaundice in $(30 \%)$ of neonates followed by asphyxia (18\%) and RDS (16\%). ${ }^{13}$ Chauhan et al also reported higher incidence of jaundice (32.3\%), RDS (22.6\%) and asphyxia (13.7\%) in their study. ${ }^{23}$

$14.5 \%$ of the neonates had Apgar score less than 7 at 1 minute in our study. On the contrary, Karegoudar et al observed that $55.28 \%$ of the babies had Apgar score less than seven. ${ }^{11}$ At 5 minutes Apgar score was less than seven in $7 \%$ in our study while in their study it was $2.48 \%$. Apgar score significantly improved as the period of gestation increased at 5 minutes and 10 minutes $(p=0.006$ and $\mathrm{p}<0.001$ respectively).

The overall mortality among preterm births was $8.1 \%$ which is lower as compared to studies done by Singh et al at $12.7 \%$ and Singh et al at $21 \% .^{8,25}$ Only $3.7 \%$ neonatal deaths were seen in gestational age 34 weeks to $<37$ weeks, whereas $24.1 \%$ and $22.2 \%$ mortality were seen in 32 weeks to $<34$ weeks and 28 weeks to $<32$ weeks of gestation 
( $\mathrm{p}=<0.001$ ). Similar findings were observed by Singh et al where neonatal mortality in babies $>34$ weeks was only $3.4 \% .^{8}$ This translates to a great benefit of prolonging pregnancy beyond 34 weeks in cases of preterm labor. In this study, birth weight is significantly associated with mortality as no deaths were reported in babies who weighed $>2 \mathrm{~kg}$. Similar findings were also reported by Garg et al. ${ }^{13}$

\section{Limitations}

The major limitations of this study were the small sample size and study population belongs to a state referral hospital. So, the results of this study may not reflect the actual scenario in the general population. Hence, we should analyse the results of this study with caution. Beside the limitatations, this study has provided the basic information on fetomaternal outcome in preterm labour in our set up and also guides to conduct further studies be carried out in different settings to elucidate the causes of preterm births to help policy makers to plan preventive measures to combat this problem, thereby decreasing infant morbidity and mortality.

\section{CONCLUSION}

Preterm infants are at high risk for overall morbidity and mortality compared with term infants. Proper antenatal care, clinical suspicion, early detection and correction of risk factors like correction of anaemia, group B of blood preeclampsia, treatment of cervicovaginal infections and asymptomatic bacteriruria, use of tocolysis in over distended uterus, abstinence, cervical cerclage in proven cases of cervical incompetence, institutional delivery and good neonatal care facilities can improve the outcome of preterm labour. This study was conducted to assess and analyse the fetomaternal outcome and suggest preventive measures that can be developed through this study. Though incidence of preterm in our study is lower compared to others, it still contributes significantly to neonatal mortality and morbidity. Proper antenatal care will help in identification of high-risk cases and plays a major role in lowering preterm births and thereby preventing complications in the newborn, as evidenced by significant association between premature births and low Apgar score and low birth weight.

Considering the significant association of preterm births and infant mortality, it is important that further studies be carried out in different settings to elucidate the causes of preterm births to help policy makers to plan preventive measures to combat this problem, thereby decreasing infant morbidity and mortality.

Funding: No funding sources Conflict of interest: None declared

Ethical approval: The study was approved by the Institutional Ethics Committee

\section{REFERENCES}

1. Goldenberg RL. The management of preterm labor. Obstet Gynecol. 2002;100(5):1020-37.

2. Loftin RW, Habli M, Snyder CC, Cormier CM, Lewis DF, Defranco EA. Late preterm birth. Rev Obstet Gynecol. 2010;3(1):10-9.

3. Adams CI. Neurodevelopmental outcome of the late preterm infant. Clin Perinatol. 2006;33(4):947-64.

4. Zahid, Rostagi A. Preterm Birth, 2016. Available at: https://nhp.gov.in/disease/reproductivesystem/female .diseases/preterm-birth. Accessed on 9 April 2021.

5. Lawn JE, Wilczynska KK, Cousens SN. Estimating the causes of 4 million neonatal deaths in the year 2000. Int J Epidemiol. 2006;35(3):706-18.

6. Petrou S, Mehta Z, Hockley C, Cook MP, Henderson J, Goldacre M. The impact of preterm birth on hospital inpatient admissions and costs during the first 5 years of life. Pediatrics. 2003;112:1290-7.

7. Petrou S. The economic consequences of preterm birth during the first 10 years of life. BJOG. 2005;112(1):10-5.

8. Singh U, Singh N, Seth S. A prospective analysis of etiology and outcome of preterm labor. J Obstet Gynaecol India. 2007;57(1):48-52.

9. Fernandes SF, Chandra S. A study of risk factors for preterm labour. Int J Reprod Contracep Obstet Gynaecol. 2015;4(5):1306-12.

10. Satija A, Satija V, Kaur J. Prospective analysis of preterm labor: Its etiology and outcome. Int J Basic Applied Med Sci. 2014;4(2):70-7.

11. Karegoudar D, Prabhu A, Kapil A. Perinatal outcome and associated maternal co-morbid conditions in late preterm births, a prospective study at Kles Dr. Prabhakar Kore Hospital, Belgaum, India. International J Curr Microbiol Applied Sci. 2014;3(6):865-75.

12. Alijahan R, Hazrati S, Mirzarahimi M, Pourfarzi F, Hadi PA. Prevalence and risk factors associated with preterm birth in Ardabil, Iran. Iran J Reprod Med. 2014;12(1):47-56.

13. Garg S, Kaur T, Saran AS, Yadav M. A study of etiology and outcome of preterm birth at a tertiary care centre. Int J Reprod Contracept Obstet Gynaecol. 2017;6(10):4488-91.

14. Naik S, Singh A. Preterm birth: its causes and perinatal outcome. Int J Sci Res. 2017;6(5):501-3.

15. Shetty MB, Krupa BM, Malyala M, Swarup A, Pathadan DS, Pocha S. Preterm birth: associated risk factors and outcome in tertiary care center. Int $\mathbf{J}$ Reprod Contracept Obstet Gynaecol. 2017;6(8):32714.

16. Shubhada A, Kambale SV, Phalke BD. Determinants of preterm labour in a rural medical college hospital in western Maharashtra. NJOG. 2013;8(1):31-3.

17. Dabbagh SA, Taee WY. Risk factors for pre-term birth in Iraq: a case-control study. BMC Pregnancy Childbirth. 2006;6:13. 
18. Shlomo E, Ehud W, Zohar N, Eliezer S. Epidemiologic risk factors for preterm delivery. Isr Med Assoc J. 2002; 4:1115-7.

19. Moreau C, Kaminski M, Ancel PY, Bouyer J, Escande $B$, Thiriez G, et al. Previous induced abortions and the risk of very preterm delivery- results of EPIPAGE study. BJOG. 2005;112(4):430-7.

20. Pool BA. Preterm labor: diagnosis and treatment. Am Fam Physician. 1998;57(10):2457-64.

21. Shreshta S, Dangol SS, Shreshta M, Shreshta RPB. Outcome of preterm babies and associated risk factors in a hospital. J Nepal Med Assoc. 2010;50(180):28690.

22. Rehana T. Preterm delivery: A major predictor of perinatal morbidity and mortality. J Postgraduate Med. 2006;20(3):279-83.
23. Chauhan N, Purohit RC, Rawat U. Analysis of Etiology and Outcome of Preterm Labour in Tertiary Health Centre of Uttarakhand. Sch J Applied Medical Sci. 2016;4(3):740-3.

24. Wright SP, Mitchell EA, Thompson JM, Clements MS, Ford RP, Stewart AW. Risk factors for preterm birth; a New Zealand study. NZ Med J. 1998;111(1058);14-6.

25. Singh D, Varghese PV, Singh S. Outcome of hospitalised out-born preterm babies. Indian J Maternal Child Health. 1992;3:4-7.

Cite this article as: Nungsangtemjen, Mahajan K, Singh MR, Mahongnao Y, Momin DG, Subba T.

Fetomaternal outcome in preterm labour. Int J

Reprod Contracept Obstet Gynecol 2021;10:2362-7. 